Fukushima J. Med. Sci.,

Vol. 52, No. 1, 2006

[Original Article]

\title{
ANTI-CALRETICULIN ANTIBODIES IN PATIENTS WITH INFLAMMATORY BOWEL DISEASE
}

\author{
KENYA WATANABE, HIROMASA OHIRA, HIROSHI ORIKASA, \\ KEIETSU SAITO, KAORI KANNO, YASUO SHIOYA, \\ KATSUTOSHI OBARA and YUKIO SATO \\ Department of Internal Medicine II, Fukushima Medical University School of Medicine, \\ Fukushima, 960-1295, Japan
}

(Received October 19, 2005, accepted December 22, 2005)

\begin{abstract}
Purpose: Although the pathogenesis of inflammatory bowel disease (IBD) is unclear, autoimmune processes seem to play roles in IBD because several types of autoantibodies have been found in it. Calreticulin (CRT) is a soluble $\mathrm{Ca}^{2+}$ binding protein which is present in a wide variety of cells. CRT is localized mainly in the endoplasmic reticulum and is often a target for autoantibodies. The aim of this study was to evaluate the clinical significance of anti-CRT antibodies measured by enzyme-linked immunosorbent assay (ELISA) using the sera of patients with ulcerative colitis (UC) and Crohn's disease (CD).

Methods: We measured the serum anti-CRT antibodies of 31 Japanese patients with UC and 24 with CD by ELISA. The controls were 105 subjects: 30 healthy persons, 44 patients with primary biliary cirrhosis (PBC), 21 with systemic lupus erythematosus (SLE) and 10 with acute colitis (AC).

Results: The mean titer of anti-CRT antibodies was significantly higher in patients with $\mathrm{UC}$ than in healthy individuals $(p<0.05)$. The prevalence of anti-CRT antibodies in these patients was significantly higher during the initial phase than during the passing phase $(p<0.05)$. In patients with $\mathrm{CD}$, the mean titer of anti-CRT antibodies was not significantly higher than in healthy individuals. The positivity for anti-CRT antibodies, however, was about 30\% in those patients, which was as high as in patients with UC, SLE and PBC. In patients with AC, anti-CRT antibodies were all negative.

Conclusions: The positivity of anti-CRT antibodies may have a diagnostic value for IBD, especially in the initial phase of UC.
\end{abstract}

Key words : calreticulin, ulcerative colitis, Crohn's disease

渡辺研也，大平弘正，折笠博史，斎藤桂悦，菅野 香，塩谷康夫，小原勝敏，佐藤由紀夫 Correspondence to: Kenya Watanabe, Department of Internal Medicine II, Fukushima Medical University School of Medicine, Fukushima City 960-1295, Japan. 


\section{INTRODUCTION}

Calreticulin (CRT) is a soluble $\mathrm{Ca}^{2+}$ binding protein which is present in a wide variety of cells ${ }^{1-3)}$. CRT is localized mainly in the endoplasmic reticulum and is often a target for autoantibodies in patients with systemic lupus erythematosus (SLE), rheumatoid arthritis (RA), Sjögren syndrome (SS), mixed connective tissue disease (MCTD), primary biliary cirrhosis (PBC) and autoimmune hepatitis (AIH). In addition to being a target for autoantibodies, this protein is implicated in complement inactivation and stimulation of inflammatory mediators. Anti-CRT antibodies are also found in the sera of patients with parasitic infections caused by Schistosoma mansoni, Trypanosoma crusi, and Plasmodium malariae, which secrete a CRT homologue ${ }^{4-12)}$.

Celiac disease (CLD) is one of the small bowel diseases characterized by villous atrophy, crypt hyperplasia and increased number of intraepithelial lymphocytes. CLD is induced in genetically susceptible individuals by dietary gliadin from wheat or by analogous proteins from rye and barley and less by oats. The sera from celiac patients contain high levels of IgG and IgA antibodies to gliadin and autoantibodies against endomysial and enterocyte antigens. The endomysial antigen has recently been identified as tissue transglutaminase. Cross-reactive enterocyte proteins were isolated and the first enterocyte antigen was identified as $\mathrm{CRT}^{13-15)}$.

Inflammatory bowel disease (IBD) consists of chronic tissue-destructive inflammatory diseases, either limited to the large bowel (ulcerative colitis, UC) or occurring anywhere along the alimentary canal (Crohn's disease, CD). The etiology of IBD has not been fully clarified; however, recent observations suggest aberrant Toll-like receptors and NOD2 signaling may stimulate diverse inflammatory responses leading to acute and chronic intestinal inflammation ${ }^{16)}$. Several types of autoantibodies, including anti-CRT antibodies, have been found in $i^{14,15}$. The aim of this study was to evaluate the clinical significance of anti-CRT antibodies measured by enzyme-linked immunosorbent assay (ELISA) using the sera of Japanese patients with $\mathrm{UC}$ and $\mathrm{CD}$.

\section{PATIENTS AND METHODS}

\section{Patients}

Fifty-five patients with IBD, i.e., 31 with UC (19 men and 12 women, aged 15 to 74 years; mean age, 34.3 years) and 24 patients with CD (17 men and 7 women, aged 16 to 68 years ; mean age, 29.1 years), were enrolled in this study. UC and CD were diagnosed on the basis of clinical, barium meal, barium enema, endoscopic and histological findings.

The activity of UC was determined by the score established by Truelove ${ }^{17}$. The patients with $\mathrm{CD}$ were divided into two groups by the IOIBD score : those in the 
active stage (IOIBD score $\leq 2$ ) and those in the remission stage (IOIBD score $\leq 1)^{18)}$.

The clinical course of UC was divided into two phases: initial and passing. The former represents a period of less than two months from the beginning of abdominal symptoms, and the latter a period of more.

Control serum samples were collected from 105 subjects : 30 healthy persons, 44 patients with PBC, 21 with SLE and 10 with acute colitis (AC).

\section{ELISA for detection of anti-CRT antibodies (IgG class)}

ELISA was done essentially as described by Engvall et al. ${ }^{19}$. . One hundred microliters of calreticulin $(0.5 \mu \mathrm{g})$ from bovine liver (Sigma Chemical Co., St. Louis, $\mathrm{MO}, \mathrm{USA}$ ) in $0.1 \mathrm{M}$ sodium carbonate-bicarbonate buffer at $\mathrm{pH} 9.6$ was added to each well of 96-well microtiter plates (Thermo, Franklin, MA, USA). The plates were then incubated overnight at $4^{\circ} \mathrm{C}$. After three washes with phosphate buffered saline (PBS) containing $0.05 \%$ Tween 20 (PBS-Tween), the wells were coated with PBS containing $1 \%$ bovine serum albumin (BSA) for 2 hours at room temperature. After three further washes with PBS-Tween, the serum samples, diluted 1:100 in PBSTween, were added to the wells in duplicate and the plates were incubated for $1 \mathrm{~h}$ at room temperature. After three further washes with PBS-Tween, $100 \mu 1$ of alkaline-phosphatase-conjugated goat $\left.\mathrm{F}(\mathrm{ab})_{2}\right)_{2}$ anti-human IgG (Tago, Camarillo, CA, USA), diluted 1:500 in PBS-Tween, was added to the wells, and the plates were incubated for $1 \mathrm{~h}$ at room temperature. Immunoreactivity was visualized using $\mathrm{p}$ nitrophenylphosphate as the substrate (Sigma), and the absorbance was measured using a spectrophotometer (Benchmark Plus, Bio-Rad, Richmond, CA, USA) at 405 $\mathrm{nm}$. Measurements were standardized using positive control with a high titer of anti-CRT antibodies from a patient with UC. This standardization was done in all ELISA tests and defined as 1,000 arbitrary unit (AU). Values greater than mean+ 2SD of the AU obtained from the sera of 30 healthy subjects were considered positive (109.1 AU).

\section{Statistical analysis}

Differences in the titers of anti-CRT antibodies as determined by ELISA were evaluated by Mann-Whitney's U test. Differences in prevalence between the antiCRT antibodies were evaluated by Fisher's extended exact test. Differences at $p$ values of less than 0.05 were considered significant.

Measurement of anti-neutrophil cytoplasmic antibodies with perinuclear staining

Anti-neutrophil cytoplasmic antibodies (ANCA) with perinuclear staining (pANCA) were measured by the fluorescent activity method (FA) in a commercial laboratory (SRL, Tokyo, Japan). 


\section{RESULTS}

Anti-CRT antibodies in patients with IBD, PBC, SLE and $A C$

The titers of anti-CRT antibodies in patients with UC, CD, PBC, SLE and AC and healthy controls are shown in Figure 1. The mean titers of anti-CRT antibodies were 168.0, 114.7, 105.3, 113.0 and $43.4 \mathrm{AU}$ in patients with UC, CD, PBC, SLE and $\mathrm{AC}$, respectively, and $61.2 \mathrm{AU}$ in healthy persons. The antibody titers for patients with UC, PBC, SLE were thus significantly higher than control $(P<0.05)$;
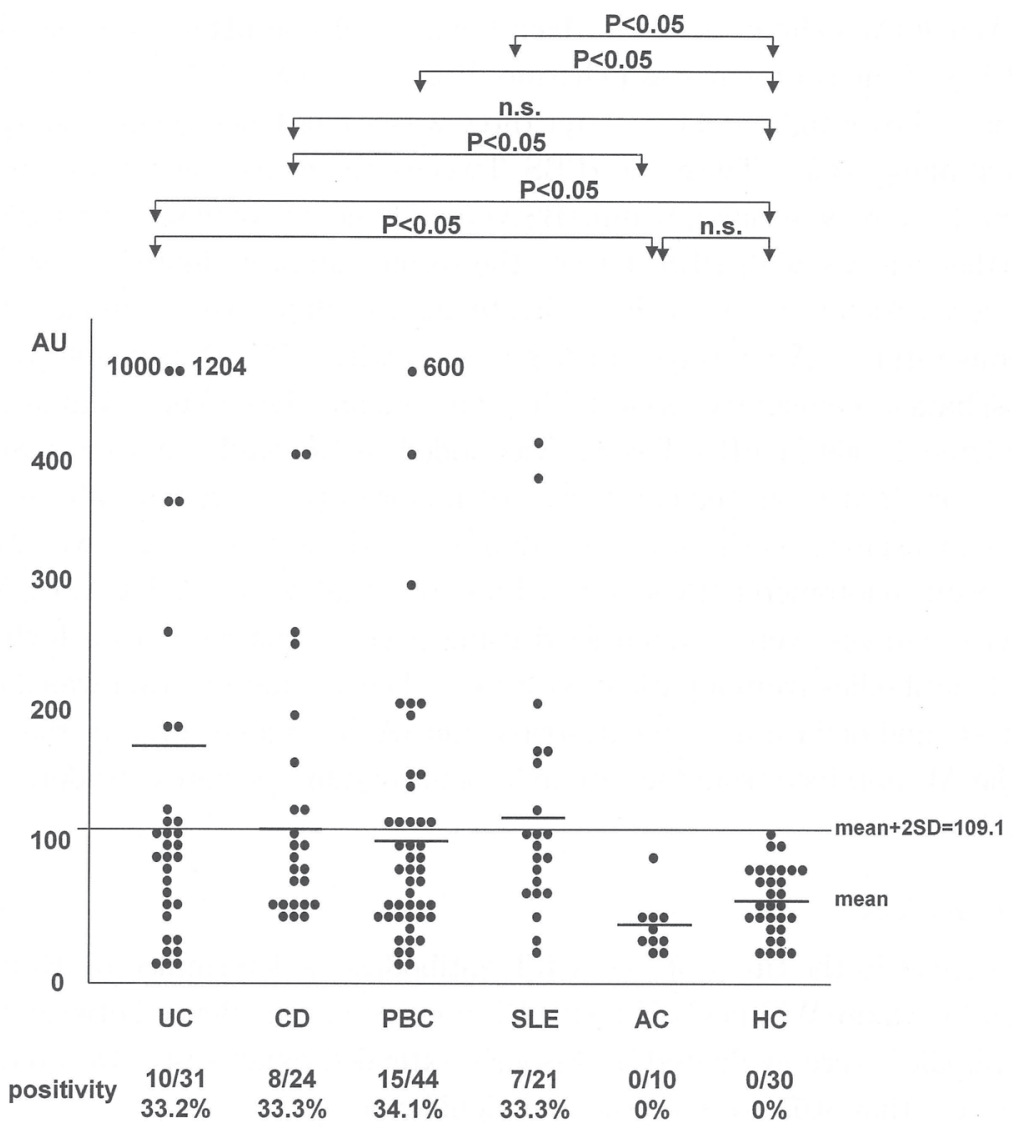

UC: ulcerative colitis, CD: Crohn's disease, SLE: systemic lupus erythematosus,

PBC: primary biliary cirrhosis, AC: acute colitis HC: healthy control

\section{AU: arbitrary unit}

Figure 1. Distribution of individual values of $\operatorname{IgG}$ antibodies to calreticulin in sera of patients with UC $(n=31), \mathrm{CD}(n=24), \operatorname{PBC}(n=44), \operatorname{SLE}(n=21), \mathrm{AC}(n=10)$ and $\mathrm{HC}(n=30)$. The IgG level is expressed in arbitrary unit. Mann-Whitney test was used for statistical comparison of antibody levels between patients and controls. 
however, the antibody titers for patients with $\mathrm{CD}$ were not. The antibody titers for patients with $U C$ and $C D$ were significantly higher than that for patients with $A C$, which did not differ significantly from control.

The prevalence of anti-CRT antibodies is also shown in Figure 1. Anti-CRT antibodies were detected in 32.2\% (10/31), 33.3\% (8/24), 34.1\% (15/44), 33.3\% (7/21) and $0 \%(0 / 10)$ of patients with $\mathrm{UC}, \mathrm{CD}, \mathrm{PBC}, \mathrm{SLE}$ and $\mathrm{AC}$, respectively, and $0 \%(0 /$ 30) of healthy individuals.

Correlation between the period from onset of IBD and the prevalence and titers of anti-CRT antibodies

The clinical course of UC was divided into two phases, the initial phase that represents a period of less than two months from the beginning of abdominal symptoms and the passing phase that represents a period of more. As shown in Table 1 , the positivities for anti-CRT antibodies were 66.6\% (6/9) and 18.2\% (4/22) in patients during the initial and passing phases, respectively, indicating significantly higher prevalence of anti-CRT antibodies in the former $(p<0.05)$. The mean titers of anti-CRT antibodies were 238.3 and $139.2 \mathrm{AU}$ in patients during the initial and passing phases, respectively.

As for patients with $\mathrm{CD}$, we were able to obtain no serum samples in the initial phase because onset was difficult to determine.

Correlation between the symptomatic grade and the prevalence and titers of anti$C R T$ antibodies in patients with IBD

The prevalence of anti-CRT antibodies was analyzed according to the symptomatic grade in patients with $\mathrm{UC}^{17}$. The positivities for anti-CRT antibodies were $33.3 \%(7 / 21)$ and $30.0 \%(3 / 10)$ in patients with moderate to severe activity and those with mild activity or in the remission stage (Table 2), respectively, showing no significant difference between the two groups. The mean titers of anti-CRT antibodies were 200.7 and $99.3 \mathrm{AU}$ in the two groups, respectively.

We divided the patients with CD into two groups by the IOIBD score ${ }^{18)}$, those in the active stage and those in the remission stage. The positivity for anti-CRT antibodies was $33.3 \%(4 / 12)$ in both patients in the active and remission stages

Table 1. Period from onset and prevalence of anti-CRT antibodies in patients with UC. Significance was calculated using Fisher's exact test.

\begin{tabular}{|c|c|c|c|}
\hline & No. of patients & No. of positive (\%) & \\
\hline initial phase & $9(*)$ & $6(66.6)$ & - \\
\hline passing phase & $22(* *)$ & $4(18.2)$ & $\neg p$ \\
\hline
\end{tabular}

initial phase : $<2$ months from beginning of abdominal symptoms passing phase: $>2$ months from beginning of abdominal symptoms mean titer measured by ELISA were $238.3 \mathrm{AU}(*)$ and $139.2 \mathrm{AU}(* *)$. 
Table 2. Symptomatic grades and prevalence of anti-CRT antibodies in patients with UC. Significance was calculated using Fisher's exact test.

\begin{tabular}{cccl}
\hline & No. of patients & No. of positive (\%) & \\
\hline moderate to severe activity & $21(*)$ & $7(33.3)$ & \\
remission or mild activity & $10(* *)$ & $3(30.0)$ & n.s. \\
\hline
\end{tabular}

mean titer measured by ELISA were $200.7 \mathrm{AU}(*)$ and $99.3 \mathrm{AU}(* *)$.

Table 3. Activity and prevalence of anti-CRT ntibodies in patients with CD. Significance was calculated using Fisher's exact test.

$\left.\begin{array}{cccl}\hline & \text { No. of patients } & \text { No. of positive (\%) } & \\ \hline \text { active stage } & 12(*) & 4(33.3) \\ \text { remission stage } & 12(* *) & 4(33.3)\end{array}\right]$ n.s.

active stage: IOIBD score $\geq 2$

remission stage : IOIBD score $\leq 1$

mean titer measured by ELISA were $110.8 \mathrm{AU}(*)$ and $118.6 \mathrm{AU}(* *)$.

(Table 3). The mean titers of anti-CRT antibodies were 110.8 and $118.6 \mathrm{AU}$ in patients in the active and remission stages, respectively.

Correlation between the extent of disease and the prevalence and titers of anti-CRT antibodies in patients with IBD

To evaluate the correlation between the extent of disease and the prevalence of anti-CRT antibodies, we distinguished the extensive colitis type of UC (disease extending to the hepatic flexure or beyond) from the left-sided colitis type. The positivities for anti-CRT antibodies were 30.8\% (8/26) and 40.0\% (2/5) in patients with extensive and left-sided colitis types of UC (Table 4), respectively, showing no significant difference between the two groups. The mean titers of anti-CRT antibodies were 138.0 and $323.8 \mathrm{AU}$ in the two groups, respectively.

We divided the patients with CD into two groups, those diseased in the ileum and those diseased in the colon, and assessed them separately. Those diseased in both the ileum and the colon comprised $62.5 \%(15 / 24)$ of the patients. The positivities for anti-CRT antibodies were $38.9 \%(7 / 18)$ and $28.6 \%(6 / 21)$ in patients diseased in the ileum and colon (Table 5), respectively, showing no significant difference between the two groups. The mean titers of anti-CRT antibodies were 121.8 and 104.1 AU in the

Table 4. Extent of disease and prevalence of anti-CRT antibodies in patients with UC. Significance was calculated using Fisher's exact test.

$\left.\begin{array}{lccl}\hline & \text { No. of patients } & \text { No. of positive (\%) } & \\ \hline \text { extensive colitis type } & 26(*) & 8(30.8) \\ \text { left-sided colitis type } & 5(* *) & 2(40.0)\end{array}\right]$ n.s.

mean titer measured by ELISA were $138.0 \mathrm{AU}(*)$ and $323.8 \mathrm{AU}(* *)$. 
Table 5. Extent of disease and prevalence of anti-CRT antibodies in patients with CD. Significance was calculated using Fisher's exact test.

\begin{tabular}{|c|c|c|c|}
\hline & No. of patients & No. of positive (\%) & \\
\hline ileal disease & $18(*)$ & $7(38.9)$ & \\
\hline colonic disease & $21(* *)$ & $6(28.6)$ & $\_$n.s. \\
\hline
\end{tabular}

mean titer measured by ELISA were 121.8 AU (*) and 104.1 AU (**).

two groups, respectively.

Correlation between surgery-free survival and the prevalence of anti-CRT antibodies in patients with IBD

Finally, to evaluate the correlation between surgery-free survival and the prevalence of anti-CRT antibodies in patients with IBD, we divided the 55 patients into two groups, those with surgery-free survival after they were enrolled in this study and those without. No patients with UC had a history of total colectomy when they were enrolled. The summarized results are shown in Table 6 and 7 . As for patients with UC, the positivities for anti-CRT antibodies were $0 \%(0 / 6)$ and $40 \%$ $(10 / 25)$ in those with a history of surgical operation and those without (Table 6), respectively, showing no significant difference between the two groups. The mean titers of anti-CRT antibodies were 55.2 and 195 AU in the two groups, respectively.

As for patients with $\mathrm{CD}$, the positivities for anti-CRT antibodies were $35.7 \%$ (5/ 14) and $30.0 \%(3 / 10)$ in those with surgical history and those without (Table 7$)$, respectively, showing no significant difference between the two groups. The mean titers of anti-CRT antibodies were 115.0 and $114.1 \mathrm{AU}$ in the two groups, respectively.

Table 6. Surgery-free survival and prevalence of anti-CRT antibodies in patients with UC. Significance was calculated using Fisher's exact test.

\begin{tabular}{cccl}
\hline & No. of patients & No. of positive (\%) & \\
\hline operations & $6(*)$ & $0(0)$ & \\
no operations & $25(* *)$ & $10(40)$ & n.s. \\
\hline
\end{tabular}

mean titer measured by ELISA were 55.2 AU (*) and 195.0 AU (**).

Table 7. Surgery-free survival and prevalence of anti-CRT antibodies in patients with CD. Significance was calculated using Fisher's exact test.

\begin{tabular}{cccl}
\hline & No. of patients & No. of positive (\%) & \\
\hline operations & $14(*)$ & $5(35.7)$ & \\
no operations & $10(* *)$ & $3(30.0)$ & \\
\hline
\end{tabular}

mean titer measured by ELISA were $115.0 \mathrm{AU}(*)$ and $114.1 \mathrm{AU}(* *)$. 
$P-A N C A$ in patients with UC

Measured in 14 of the $31 \mathrm{UC}$ serum samples, P-ANCA were negative in all samples, whereas the positivities for anti-CRT antibodies were $21.4 \%(3 / 14)$.

\section{DISCUSSION}

Anti-CRT antibodies are found in the sera of patients with various autoimmune diseases, such as SLE and $\mathrm{PBC}^{4,5,9,11,12)}$. We thought it proper to use bovine CRT for ELISA in this study, because Chen and his colleague proved that the peptides in bovine CRT are very similar in structure to those in human CRT ${ }^{20}$. We assessed the prevalence of anti-CRT antibodies in patients with PBC and SLE, and compared the results with those previously reported. The prevalences of anti-CRT antibodies obtained in this study were $33.3 \%$ and $34.1 \%$ for patients with SLE and PBC, respectively. These values are so similar to those (33-75\%, 43\%) obtained by other investigators ${ }^{4,5,9,11)}$ that we consider our values for patients with $\mathrm{UC}(32.2 \%)$ and $\mathrm{CD}$ (33.3\%) are also reliable. Sánchez and his colleague reported that the positivity for anti-CRT antibodies was about $20 \%$ in patients with $\mathrm{IBD}^{14)}$. Our values were higher than that, especially in the initial phase of UC (62.5\%). And the titers of anti-CRT antibodies in patients with UC were significantly higher than those in healthy individuals.

A variety of serological tests that are relevant to the diagnosis and treatment of IBD are emerging. P-ANCA, the most common antibody in patients with UC, was first described in patients with glomerulonephritis and systemic vasculitis ${ }^{21,22}$. The prevalence of ANCA in patients with UC ranges from $54 \%$ to $89 \%^{23-26)}$, and that of $\mathrm{p}$-ANCA from $31.5 \%$ to $57 \%^{25-27)}$. These values are higher than the prevalence of anti-CRT antibodies in patients with UC obtained in this study. However, pANCA were negative in all samples, whereas the positivities for anti-CRT antibodies were $21.4 \%$. This contradiction may have been due to the difference in sensitivity between ELISA and FA. ELISA, however, is not practical for measurement of $\mathrm{p}$-ANCA because it has various target antigens in the sera of UC. Moreover, there are many cases that are difficult to diagnose as IBD, ruling out other colitic disorders. In many cases of IBD, indeterminate colitis and unclassified colitis caused by autoimmunity, ANCA testing is too specific to use as the first diagnostic test. Less specific serological tests, such as the anti-CRT antibody test, may be helpful in determining the participation of autoimmunity.

The prevalence of anti-CRT antibodies was significantly higher in patients with UC during the initial phase than in those during the passing phase. This finding may mean that the anti-CRT antibody test is more sensitive to the initial phase of IBD or autoimmune colitic disorders, increasing the diagnostic value of anti-CRT antibodies for IBD.

The etiology of IBD remains to be clarified. Recently, Brimnes and his col- 
leagues reported that $\mathrm{CD} 8^{+} \mathrm{T}$ cells with regulatory activity, which play an active role in mucosal tolerance, are not present in the lamina propria in patients with IBD ${ }^{28)}$. CRT has previously been implicated in the priming of $\mathrm{CD} 8^{+} \mathrm{T}$ cells. Small amounts of peptide could elicit a specific $\mathrm{CD} 8^{+}$response only if they were bound to $\mathrm{CRT}^{29,30)}$. Thus, the appearance of anti-CRT antibodies may play important roles in the destruction of mucosal tolerance in patients with IBD.

We cannot comment on the correlation of anti-CRT antibodies and the disease activity of IBD, because the prevalence of anti-CRT antibodies was not significantly higher in patients with moderate to severe activity than in those with mild activity or in the remission stage. Immunosuppressive agents like steroids, azathioprine and sulfasalazine may have lowered the prevalence of anti-CRT antibodies.

Sandborn and his colleagues reported an association between ANCA positivity in the setting of left-sided ulcerative colitis and resistance to medical therapy ${ }^{313}$. This study showed no significant correlation between the diseased lesion, prognosis and the prevalence of anti-CRT antibodies in patients with IBD.

In conclusion, we have shown that the prevalence of anti-CRT antibodies is as high in patients with UC as in patients with SLE or PBC. The positivity of antiCRT antibodies may have a diagnostic value in IBD, especially in the initial phase of UC, indicating the participation of autoimmunity in patients with colitic disorders.

\section{REFERENCES}

1. Rokeach LA, Haselby JA, Meilof JF, Smeenk RJT, Unnasch TR, Greene BM, Hoch SO. Charaterization of the autoantigen calreticulin. J Immunol, 147: 3031-3039, 1991.

2. Michalak M, Milner RE, Burns K, Opas M. Calreticulin. Biochem J, 285: 681-692, 1992.

3. Sontheimer RD, Nguyen TQ, Cheng. ST, Lieu TS, Capra JD. The unveiling of calreticulin - a clinically relevant tour of modern cell biology. J Invest Med, 43: 362370, 1995.

4. Kishore U, Sontheimer RD, Sastry KN, Zappi EG, Hughes GRV, Khamashta MA, Reid KDM, Eggleton P. The systemic lupus erythematosus (SLE) disease autoantigencalreticulin can inhibit C1q association with immune complex. Clin Exp Immunol, 108: 181-190, 1997.

5. Routsias JG, Tzioufas AG, Sakarellos-Daitsiotis M, Sakarellos C, Moutsopoulos HM. Calreticulin synthetic peptide analogues: anti-peptide antibodies in autoimmune rheumatic diseases. Clin Exp Immunol, 91 : 437-441, 1993.

6. Eggleton P, Llewellyn DH. Pathophysiological roles of calreticulin in autoimmune disease. Scand J Immunol, 49: 466-473, 1999.

7. Le Naour F, Brichory F, Misek DE, Bréchot C, Hanash SM, Beretta L. A distinct repertoire of autoantibodies in hepatocellular carcinoma identified by proteomic analysis. Mol Cell Proteomics, 1: 197-203, 2002.

8. Khalife J, Trottein F, Schacht AM, Godin C, Pierce RJ, Capron A. Cloning of the gene encoding a Schistosoma mansoni antigen homologous to human Ro/SS-A autoantigen. Mol Biochem Parasitol, 57 : 193-202, 1993.

9. Boehm J, Orth T, Van Ngyuyen P, Söling HD. Systemic lupus erythematosus is 
associated with increased autoantibody titers against calreticulin and Grp94, but calreticulin is not the Ro/SS-A antigen. Eur J Clin Invest, 24 : 248-257, 1994.

10. Rokeach LA, Zimmerman PA, Unnasch TR. Epitopes of the Onchocerca volvulus RAL1 antigen, a member of the calreticulin family of proteins, recognized by sera from patients with Onchocersiasis. Infect Immun, 62: 3696-3704, 1994.

11. Kreisel W, Siegel A, Bahler A, Spamer C, Schiltz E, Klein R. High prevalence of antibodies to calreticulin of the IgA class in primary biliary cirrhosis : a possible role of gut-derived bacterial antigens in its aetiology? Scand Univ Press, 6 : 623-628, 1999.

12. Sánchez D, Tučková L, Mothes T, Kreisel W, Bene? Z, Tlaskalová-Hogenová H. Epitopes of calreticulin recognized by IgA autoantibodies from patients with hepatic and celiac disease. J Autoimmun, 21 : 383-392, 2003.

13. Krupičková S, Tučková L, Flegelová Z, Michalak M, Walter JRF, Whelan A, Harries J, Vencovsky J, Tlaskalová-Hogenová H. Identification of common epitopes on gliadin, enterocytes, and calreticulin recognized by antigliadin antibodies of patients with coeliac disease. Gut, 44: 168-173, 1999.

14. Sánchez D, Tučková L, Šebo P, Michalak M, Whelan A, Sterzl I, Jelínková L, Havrdová E, Imramovská M, Beně̌ Z, Krupičková S, Tlaskalová-Hogenová H. Occurrence of IgA and IgG autoantibodies to calreticulin in coeliac disease and various autoimmune diseases. J Autoimmun, 15: 441-449, 2000.

15. Natter S, Granditsch G, Reichel GL, Baghestanian M, Valent P, Elfman L, Grönlund H, Kraft D, Valenta R. IgA cross-reactivity between a nuclear autoantigen and wheat proteins suggests molecular mimicry as a possible pathomechanism in celiac disease. Eur J Immunol, 31 : 918-928, 2001.

16. Cario E. Bacterial interactions with cells of the intestinal mucosa : Toll-like receptors and NOD2. Gut, 54: 1182-1193, 2005.

17. Truelove SC, Witts LJ. Cortisone in ulcerative colitis: final report on a therapeutic trial. Br Med J, 2: 1041-1048, 1955.

18. de Dombal FT, Softley A. IOIBD report no 1: Observer variation in calculating indices of severity and activity in Crohn's disease. International Organisation for the Study of Inflammatory Bowel Disease. Gut, 28: 474-481, 1987.

19. Engvall E, Perlmann P. Enzyme-linked immunosorbent assay (ELISA) : quantitative assay of immunoglobulin G. Immunochemistry, 8: 871-874, 1971

20. Chen D, Duggan C, Reden TB, Kooragayala LM, Texada DE, Langford MP. Calreticulin is a binding protein for muramyl dipeptide and peptidoglycan in $\mathrm{RK}_{13}$ cells. Biochem, 43 : 11796-11801, 2004.

21. Sandborn WJ. Serologic markers in inflammatory bowel disease : state of the art. Rev Gastroenterol Disord, 4: 167-174, 2004.

22. Davies DJ, Moran JE, Niall JF, Ryan GB. Segmental necrotizing glomerulonephritis with anti-neutrophil antibody : possible arbovirus aetiology? Br Med J, 285 : 606, 1982.

23. Duerr RH, Targan SR, Landers CJ, Sutherland LR, Shanahan F. Anti-neutrophil cytoplasmic antibodies in ulcerative colitis : comparison with other colitides/diarrheal illness. Gastroenterol, 100 : 1590-1596, 1991.

24. Cambridge G, Rampton DS, Stevens TRJ, McCarthy DA, Kamm M, Leaker B. Antineutrophil antibodies in inflammatory bowel disease: prevalence and diagnostic role. Gut, 33 : 668-674, 1992.

25. Sung JY, Chan KL, Hsu R, Liew CT, Lawton WM. Ulcerative colitis and antineutrophil cytoplasmic antibodies in Hong Kong Chinese. Am J Gastroenterol, 88 : 864-869, 1993.

26. Ruemmele FM, Targan SR, Levy G, Dubinsky M, Braun J, Seidman EG. Diagnostic accuracy of serological assays in pediatric inflammatory bowel disease. Gastroenterol, 115 : 822-829, 1998.

27. Quinton JF, Sendid B, Reumaux D, Duthilleul P, Cortot A, Grandbastien B, Charrier G, Targan SR, Colombel JF, Poulain D. Anti-Saccharomyces cerevisiae mannan antibodies combined with antineutrophil cytoplasmic autoantibodies in inflammatory bowel 
disease: prevalence and diagnostic role. Gut, 42: 788-791, 1998.

28. Brimnes J, Allez M, Dotan I, Shao L, Nakazawa A, Mayer L. Defects in CD8 ${ }^{+}$ regulatory $\mathrm{T}$ cells in the laminapropria of patients with inflammatory bowel disease. J immunol, 174: 5814-5822, 2005.

29. Basu BS, Srivastava PK. Calreticulin, a peptide-binding chaperone of the endoplasmic reticulum, elicits tumor- and peptide-specific immunity. J Exp Med, 189: 797-802, 1999.

30. Nair SN, Wearsch PA, Mitchell DA, Wassenberg JJ, Gilboa E, Nicchitta CV. Calreticulin displays in vivo peptide-binding activity and can elicit CTL responses against bound peptides. J Immunol, 162: 6426-6432, 1999.

31. Sandborn WJ, Landers CJ, Tremaine WJ, Targan SR. Association of antineutrophil cytoplasmic antibodies with resistance to treatment of left-sided ulcerative colitis: results of a pilot study. Mayo Clin Proc, 71: 131-136, 1996. 